\title{
Eosinofilias Pulmonares: Hallazgos que un radiólogo debe conocer
}

\section{Pulmonary Eosinophilias: Findings that a Radiologist Should Know}

\author{
Juliana Couture ${ }^{1}$ Daniel Adri ${ }^{1}$ Juan Manuel Villegas ${ }^{1}$ Natalia Posadas ${ }^{1}$ Alberto Seehaus ${ }^{1}$ \\ ${ }^{1}$ Servicio de Diagnóstico por Imágenes, Hospital Italiano de Buenos \\ Aires, Ciudad Autónoma de Buenos Aires, Argentina \\ Rev Argent Radiol 2019;83:113-120. \\ Address for correspondence Daniel Adri, PhD, JL Borges $2174,9^{\circ} \mathrm{C}$, \\ Ciudad Autónoma de Buenos Aires, Argentina \\ (e-mail: danieladri33@gmail.com).
}

\section{Resumen \\ Palabras clave \\ - síndrome hipereosinofílico \\ - eosinofilia pulmonar \\ - tomografía computada multidetector}

Las eosinofilias pulmonares incluyen un amplio espectro de desórdenes. Su diagnóstico definitivo se realiza con la anatomía patológica. No obstante, a través de los antecedentes clínicos, el examen físico y -cada vez de forma más precisa- las imágenes, podemos llegar a una mejor definición de la patología. Hoy en día, la tomografía computada multidetector (TCMD) de alta resolución es el método por imágenes de mayor sensibilidad y especificidad, ya que permite una valoración de la patología pulmonar difusa cada vez más acertada, evitando así métodos más invasivos, aportando detallada información y manifestando lesiones que carecen de una expresión clínica específica por medio de patrones radiológicos característicos.

Pulmonary eosinophilias include a broad spectrum of disorders. Its definitive diagnosis is made with the pathological anatomy. However, through the clinical history, the physical examination and the images we can have access to a more precise definition of the pathology. Today, high resolution multislice computed tomography (MSCT) is the most sensitive and specific imaging method, allowing an accurate assessment of diffuse pulmonary pathology, thus avoiding the most invasive methods, providing detailed information and stating that lack a specific clinical expression by means of characteristic radiological patterns.

\section{Introducción}

Las eosinofilias pulmonares son desórdenes infecciosos y no infecciosos asociados a eosinofilia periférica (marcador de valor patológico, siendo mayor a $\left.0,5 \times 10^{9} / \mathrm{L}\right)^{1,2}$ con eosinofilia tisular confirmada con biopsia pulmonar 0 recuento elevado de eosinófilos (25\%) en el lavado

(D) Daniel Adri's ORCID is https://orcid.org/0000-0001-8385-0497. broncoalveolar (BAL). ${ }^{3-5}$ Se pueden clasificar en: idiopáticos (neumonía eosinófila aguda, neumonía eosinófila crónica y síndrome de hipereosinofilia idiopático), secundarios a una causa infecciosa (aspergillus fumigatus) o asociadas a vasculitis y granulomatosis (síndrome de Churg Strauss, granulomatosis con poliangeitis, granulomatosis broncocéntrica o enfermedad de Sjogren). ${ }^{5}$ Si bien el gold standard para el diagnóstico es la biopsia pulmonar (cada vez más reemplazada por el $\mathrm{BAL}$ ), la tomografía computada multidetector (TCMD) de alta resolución, al tener mayor received

June 11, 2018

accepted

July 8, 2019
DOI https://doi.org/

$10.1055 / \mathrm{s}-0039-1695019$.

ISSN 1852-9992.
Copyright @ $\odot 2019$, Sociedad Argentina de Radiología. Publicado por Thieme Revinter Publicações Ltda., Rio de Janeiro, Brazil. Todos los derechos reservados.

\section{License terms}

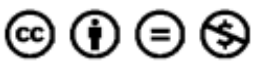


sensibilidad y especificidad que la radiología convencional, es el método de imágenes de elección para la valoración exacta de la patología pulmonar difusa, preferentemente con espesor de corte menor a $1,5 \mathrm{~mm}{ }^{6}$ En esos síndromes, el compromiso pulmonar es frecuente. Sin embargo, en la etapa temprana los hallazgos radiológicos pueden ser sutiles, de manera que la TCMD aporta detallada información y pone de manifiesto lesiones que carecen de una expresión clínica específica. ${ }^{7} \mathrm{~A}$ continuación, analizaremos los hallazgos radiológicos más característicos de los síndromes eosinofílicos a través de la $\operatorname{TCMD}(-$ Tabla 1$)$.

\section{Eosinofilias pulmonares idiopáticas}

\section{Síndrome de Loeffler o eosinofilia pulmonar simple}

Entidad de causa idiopática que se caracteriza por la ausencia de síntomas o, si los presenta, son leves e inespecíficos (tos, disnea y febrícula) con resolución en un mes. En radiología simple, se presenta como áreas radiopacas parcheadas de distribución periférica. Mediante TCMD se detectan opacidades en vidrio esmerilado o consolidativas con nódulos periféricos satélites y engrosamiento de las paredes bronquiales. No presenta efusiones pleurales ni adenopatías. $^{2}$

\section{Neumonía Eosinofílica Aguda (NEA)}

Como su nombre lo indica, se caracteriza por una infiltración rápidamente progresiva de eosinófilos en los pulmones, lo que lleva a una insuficiencia respiratoria, distinguiéndose de la presentación más indolente y menos grave de la neumonía eosinofílica crónica. ${ }^{2,8}$ De etiología desconocida, con ligero predominio en hombres, se asocia con la exposición a varios antígenos, siendo el tabaco el más frecuente. ${ }^{9}$ Se presenta con un episodio febril agudo que dura de 1 a 5 días, mialgias, dolor pleurítico y falla respiratoria puesta de manifiesto por una hipoxemia severa, es decir $\mathrm{PaO} 2$ (presión arterial de oxigeno) menor al $60 \mathrm{~mm} \mathrm{Hg}$ (milímetros de mercurio), sin evidencia de compromiso extrapulmonar. El BAL muestra un recuento elevado mixto con aumento de linfocitos y eosinófilos (más del $25 \%)^{9}$

Los hallazgos tomográficos más característicos son opacidades bilaterales en vidrio esmerilado con engrosamiento de los septos interlobulillares y derrame pleural. A pesar de que la clínica es inespecífica y el recuento de eosinófilos aumentados en sangre periférica puede estar ausente, siempre debe pensarse esta patología en una persona sana que comienza con falla respiratoria aguda de origen desconocido y los signos radiológicos previamente mencionados (-Fig. 1). ${ }^{10}$

Tabla 1 Resumen de hallazgos

\begin{tabular}{|c|c|c|c|}
\hline Entidad & Clinica & Hallazgos $R X$ & Hallazgos TCMD \\
\hline $\begin{array}{l}\text { EPI: } \\
\text { S. Loeffler }\end{array}$ & Inespecífica/Ausente & $\begin{array}{l}\text { Radioopacidades parchaeadas } \\
\text { periféricas }\end{array}$ & $\begin{array}{l}\text { Opacidades en VE/consolidativas }+ \\
\text { nódulos satélites + engrosamiento } \\
\text { peribronquial }\end{array}$ \\
\hline EPI: NEA & $\begin{array}{l}\text { S. Febril + Insuficiencia respiratoria } \\
\text { de origen desconocido }\end{array}$ & \multicolumn{2}{|c|}{$\begin{array}{l}\text { Opacidades bilaterales VE+ engrosamiento septos interlobulillares }+ \\
\text { derrame pleural. }\end{array}$} \\
\hline EPI: NEC & $\begin{array}{l}\text { S. sistémico + manifestaciones } \\
\text { pulmonares }\end{array}$ & \multicolumn{2}{|c|}{$\begin{array}{l}\text { Consolidaciones multifocales densas bilaterales localizadas en la periferia } \\
\text { de los campos pulmonares. }\end{array}$} \\
\hline EPI: SHE & $\begin{array}{l}\text { Dermatológica + pulmonar }+ \\
\text { cardíaco }\end{array}$ & \multicolumn{2}{|c|}{$\begin{array}{l}\text { Áreas reticulares parcheadas + nódulos mal definidos que pueden tener o } \\
\text { no halo de VE+ derrame pleural }(50 \%)\end{array}$} \\
\hline $\begin{array}{l}\text { EPS: } \\
\text { Aspergilosis }\end{array}$ & 5 estadios & $\begin{array}{l}\text { Opacidad tubular en "dedos de } \\
\text { guante" + distribución bronquial+ } \\
\text { campos pulmonares superior y } \\
\text { central + bronquiectasis y fibrosis }\end{array}$ & $\begin{array}{l}\text { Consolidaciones de impactación } \\
\text { mucoide + bronquiectasias } \\
\text { segmentaria y subsegmentarias de } \\
\text { los lóbulos superiores + nódulos } \\
\text { centrolobulares. }\end{array}$ \\
\hline EPV: SCS & Vasculitis de pequeños vasos & $\begin{array}{l}\text { Consolidación no Segmentarias } \\
\text { bilaterales +transitorias. }\end{array}$ & $\begin{array}{l}\text { Consolidaciones simétricas y } \\
\text { periféricas +engrosamientos de } \\
\text { septos + derrame }(50 / 10 \% \text { por falla } \\
\text { cardiaca)+ hallazgos relacionados } \\
\text { al asma }\end{array}$ \\
\hline EPV: GP & $\begin{array}{l}\text { Enfermedad pulmonar }+ \text { sinusitis } \\
+ \text { glomerulonefritis. }\end{array}$ & \multicolumn{2}{|c|}{$\begin{array}{l}\text { Nódulos + cavitaciones + predilección por los ápices pulmonares + } \\
\text { subpleurlaes + "signos del halo"+ compromiso de vía aérea. }\end{array}$} \\
\hline EPV: GSN & Vasculitis pulmonar & \multicolumn{2}{|c|}{$\begin{array}{l}\text { Nódulos bilaterales }+ \text { subpleural y peribroncovascular }+ \text { cavitaciones }+ \\
\text { realce } C E V+\text { ganglios mediastinales }+ \text { granulomas subpleurales difusos }+ \\
\text { fibrosis }\end{array}$} \\
\hline EPV: SS & Sequedad bucal y ocular & \multicolumn{2}{|c|}{$\begin{array}{l}\text { Neumonía intersticial no especifica + bronquio o bronquioloectasias + } \\
\text { engrosamientos de la pared bronquial + quistes aéreos + afectación } \\
\text { tímica }\end{array}$} \\
\hline
\end{tabular}

Abreviaturas: CEV, contraste endovenoso; EPI, eosinofilia pulmonar idiopatica; EPS, eosinofilia pulmonar secundaria; EPV, eosinofilia pulmonar asociada a vasculitis; GP, granulomatosis con poliangeitis; GSN, granulomatosis sarcoidea necrotizante; NEA, neumonía eosinofilica aguda; NEC, neumonía eosinofilica cronica; SCS, síndrome de Churg - Strauss; SHE, síndrome hiper eosinofilico; SS, Síndrome de Sjögren; VE, vidrio esmerilado. 


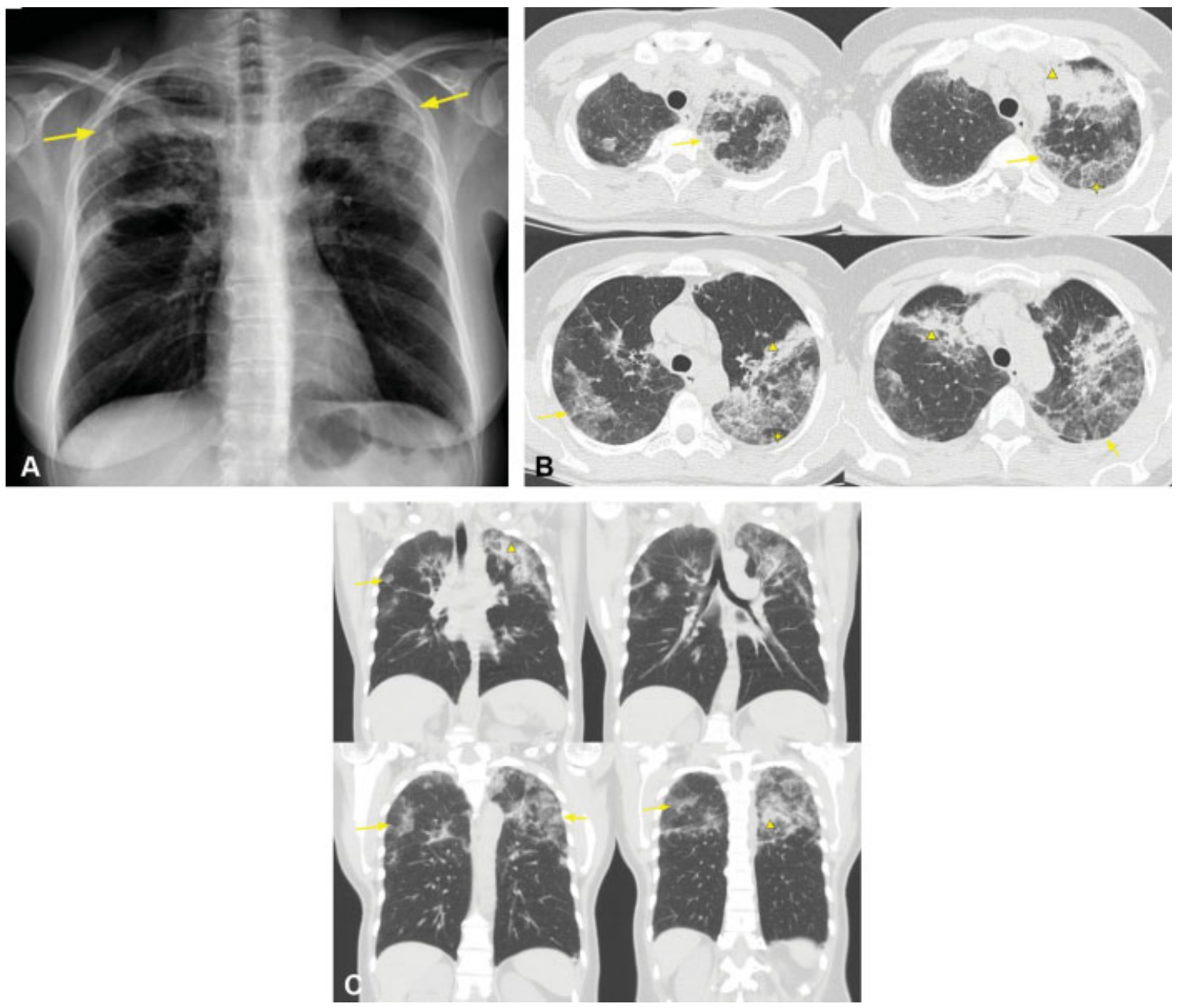

Fig. 1 Neumonía eosinofílica aguda. Paciente de sexo femenino, 49 años de edad con antecedente de tos y síndrome febril. (A) Radiografía (Rx) de tórax incidencia anteroposterior, en la que se identifican áreas de disminución en la transparencia en el tercio superior de ambos campos pulmonares (flechas). TCMD de tórax en plano axial (B) y coronal (C), que demuestra múltiples áreas de aumento en la atenuación del parénquima pulmonar en vidrio esmerilado ambos lóbulos superiores (flechas), asociado a engrosamiento de los septos interlobulillares (estrella) y sectores sutiles con tendencia a la consolidación de distribución predominantemente subpleural (cabeza de flecha). Como complemento, el análisis de laboratorio arroja un resultado de 15.000 cel/mm3 de leucocitos con 34\% de eosinófilos.

\section{Neumonía Eosinofílica Crónica (NEC)}

Es un trastorno poco frecuente, caracterizado por manifestaciones sistémicas y pulmonares, eosinofilia en sangre, opacidades periféricas en la radiografía de tórax y una pronta respuesta a los corticosteroides..$^{11}$ Predomina en personas no tabaquistas, de sexo femenino, y no genera hipoxemia severa ni falla respiratoria aguda. El recuento del BAL se encuentra elevado. La radiología muestra consolidaciones multifocales densas bilaterales localizadas en la periferia de los campos pulmonares (-Fig. 2). ${ }^{9}$

\section{Síndrome Hipereosinofílico (SHE)}

El término "síndrome hipereosinofílico", se refiere a una serie de trastornos caracterizados por números elevados de eosinófilos en sangre circulante, acompañados de infiltración de órganos terminales que conducen a la enfermedad clínica. ${ }^{8}$ Se define como SHE a la presencia de eosinofilia mayor a $1.500 / \mathrm{mm}^{3}$ en dos o más ocasiones o síntomas sugestivos de eosinofilia tisular con eosinofilia sanguínea con causas secundarias excluidas. La edad promedio de aparición es de 50 años, con predominio femenino. ${ }^{2}$ Sin embargo, puede presentarse en niños. A pesar de que las manifestaciones dermatológicas son las iniciales, en segundo lugar se afecta el pulmón (40\%) y el compromiso cardíaco es el responsable de la morbimortalidad. ${ }^{4,9}$ Los hallazgos tomográficos muestran áreas de mayor densidad reticulares con distribución parcheada, nódulos mal definidos que pueden tener o no halo de vidrio esmerilado a su alrededor. El derrame pleural se asocia en la mitad de los casos. También se pueden observar áreas difusas de vidrio esmerilado sugerentes de edema ( - Fig. 3$)^{12}$

\section{Eosinofilias pulmonares secundarias}

\section{Aspergilosis broncopulmonar alérgica}

Enfermedad infecto contagiosa que puede ser dividida en cinco etapas para ayudar a guiar el tratamiento: agudo, remisión, exacerbación, esteroides-dependiente y fibrótica. Los hallazgos en estadios tempranos suelen incluir opacidades pulmonares homogéneas transitorias, áreas de mayor opacidad tubulares en "dedos de guante" con distribución bronquial que involucra exclusiva o predominantemente los campos pulmonares superior y central. Esas opacidades están 

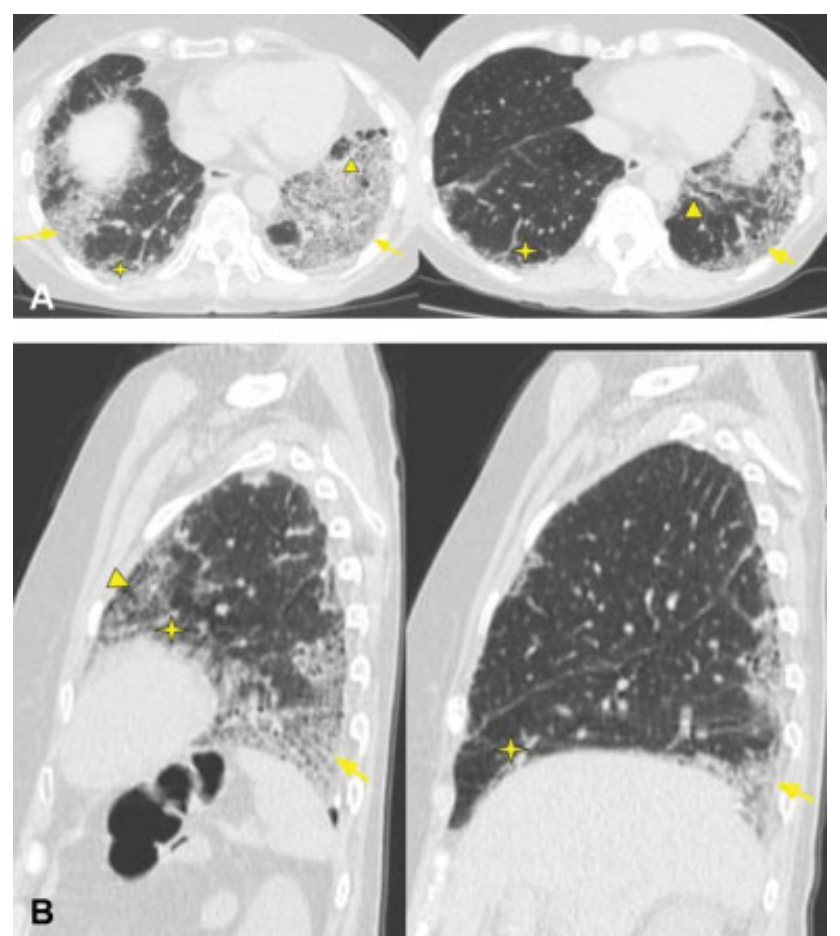

Fig. 2 Neumonía eosinofílica crónica. TCMD de tórax en plano axial (A) y plano sagital (B), donde se evidencian múltiples áreas de disminución en la transparencia del parénquima pulmonar en vidrio esmerilado, comprometiendo ambos lóbulos inferiores con predominio del izquierdo (flecha), se asocia a engrosamiento de los septos interlobulillares (estrella), bronquioloectasias por tracción y pequeñas imágenes quísticas subpleurales (cabeza de flecha), sin evidencia clara de panalización. El BAL revela extendido citológico con numerosas células bronquiales linfocitos y macrófagos, hallazgos compatibles con proceso intersticial crónico.

relacionadas con el taponamiento de las vías respiratorias por masas de hifas e impactación mucoide distal. Ocasionalmente, puede observarse atelectasia lobar o segmentaria. En estadios avanzados se desarrollan bronquiectasias centrales y fibrosis pulmonar. Los hallazgos más característicos de la TCMD consisten principalmente en impactación mucoide y bronquiectasias con predominio segmentario y subsegmentario de los lóbulos superiores, junto con nódulos centrolobulares (-Fig. 4). ${ }^{5}$

\section{Eosinofilias parasitarias}

Entre los organismos etiológicos se pueden mencionar: strongyloidiasis, ascariasis, schistosomiasis y paragonimiasis. La región geográfica determina la prevalencia de esas infecciones, así como la historia de viajes del paciente. Pueden determinar un cuadro como una eosinofilia pulmonar simple, con manifestaciones en TCMD como nódulos u opacidades o ambos. ${ }^{2}$

\section{Eosinofilias [pulmonares asociadas a vasculitis y granulomatosis]}

\section{Sindrome de Churg Strauss (SCS)}

El síndrome de Churg-Strauss es una condición en la que la vasculitis y la infiltración eosinófila potencialmente involucran

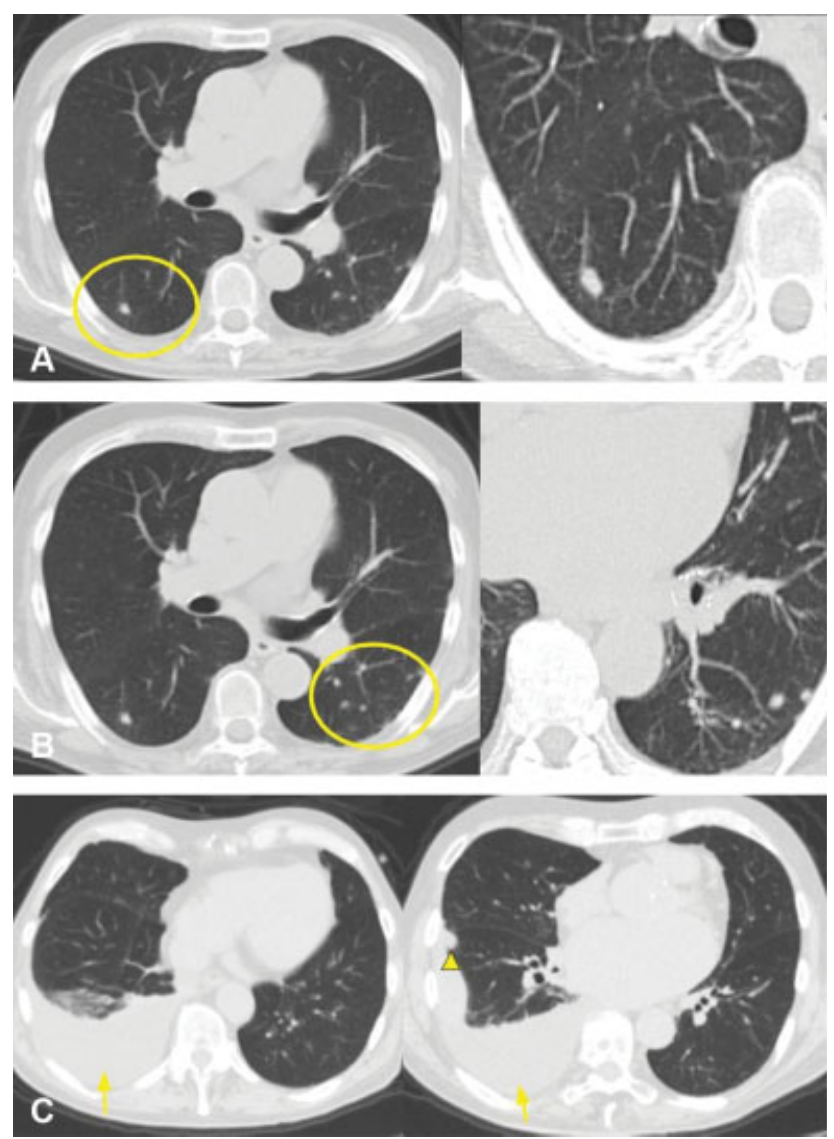

Fig. 3 Síndrome hipereosinofílico. TCMD de tórax en plano axial (A, B) con zoom en zona de interés, que evidencia múltiples formaciones nodulares/nodulillares sólidas en ambos lóbulos inferiores (círculo) en contexto de paciente con diagnóstico clínico de síndrome hipereosinofílico. (C) Mismo paciente con otra intercurrencia, con derrame pleural (flecha) y engrosamientos pleurales focales $y$ nodulares (cabeza de flecha).

múltiples órganos, incluyendo los senos, los pulmones, los nervios periféricos, el corazón, la piel, el tracto gastrointestinal y los riñones. $^{8}$ También llamada granulomatosis alérgica, fue descrita por Churg y Strauss en 1951, bajo los criterios de inflamación tisular por eosinófilos, vasculitis necrotizante y granulomas. Es una vasculitis de pequeños vasos que afecta primordialmente al pulmón. ${ }^{9}$ En la actualidad, existen seis criterios establecidos por el Colegio Americano de Reumatología para establecer el diagnóstico. Los criterios son: asma, eosinófilos periféricos mayores al 10\%, neuropatía, opacidades pulmonares permanentes o transitorias, anormalidades en los senos paranasales y eosinófilos extravasculares revelados por biopsia. ${ }^{13}$ Afecta a hombres y mujeres por igual durante la cuarta y la quinta década de vida. ${ }^{9}$

Las manifestaciones más comunes en la radiografía de tórax son áreas de consolidación no segmentarias bilaterales, transitorias, sin predilección por alguna zona pulmonar. En la TCMD, en el 90\% de los pacientes, se evidencian áreas de aumento de la atenuación en vidrio esmerilado o consolidativas bilaterales. Usualmente esas opacidades son simétricas y predominan en la periferia. También se observan bandas fibrosas en el $50 \%$ de los casos. El engrosamiento de los septos interlobulillares refleja la 


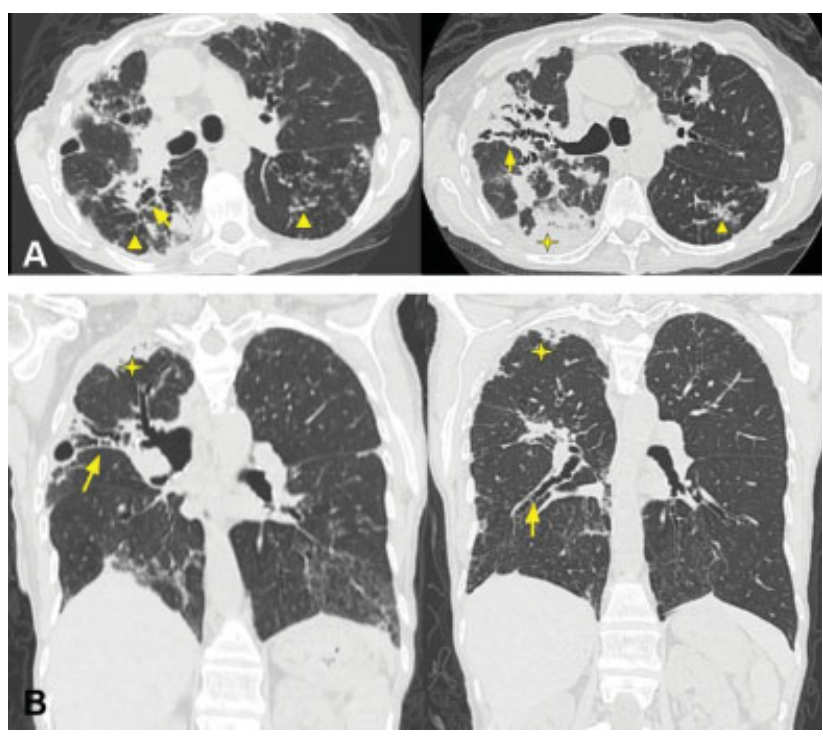

Fig. 4 Aspergilosis broncopulmonar alérgica. TCMD de tórax en plano axial (A) y plano coronal (B). Múltiples bronquiectasias en ambos lóbulos superiores (flecha) asociadas a infiltrados nodulillares con patrón en árbol en brote con compromiso de la pequeña vía aérea e impactaciones endobronquiales (cabeza de flecha). Opacidades subpleurales correspondientes a pequeñas zonas de atelectasia distal (estrella) en un paciente con diagnóstico de aspergilosis broncopulmonar alérgica.

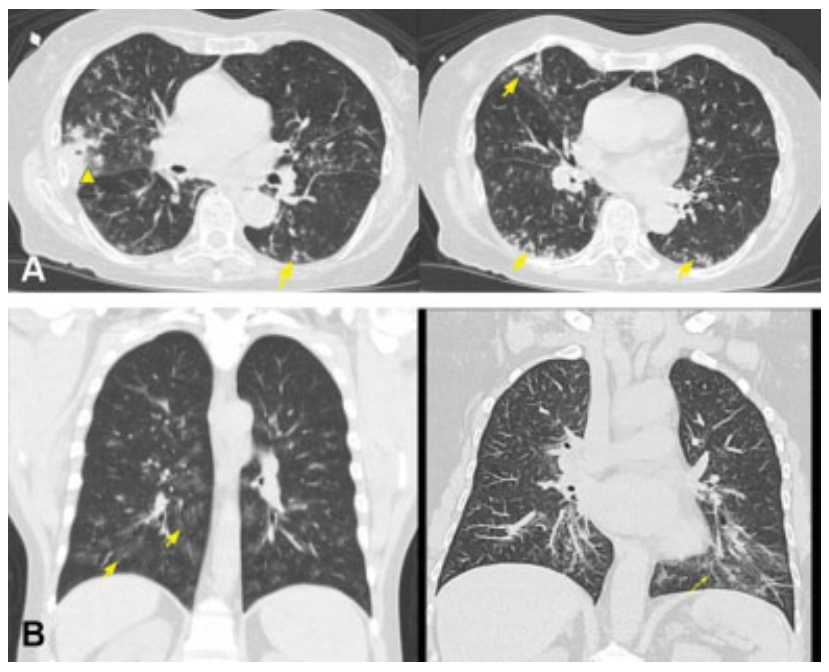

Fig. 5 Síndrome de Churg Strauss (SCS). TCMD de tórax en plano axial (A), plano coronal y reconstrucción coronal con técnica de máxima intensidad de proyección (MIP) (B). Múltiples opacidades focales, de aspecto nodulillar con densidad en vidrio esmerilado en ambos campos pulmonares con patrón en árbol en brote (flecha). Áreas de consolidación del parénquima pulmonar en el segmento posterior del lóbulo superior derecho (cabeza de flecha) en contexto de paciente con diagnóstico de Churg Strauss.

presencia de edema secundario al compromiso cardíaco o la propia infiltración de eosinófilos en el mismo. El compromiso aéreo se evidencia con nódulos centrolobulillares pequeños, patrón de árbol en brote, dilatación bronquial, engrosamiento de las paredes bronquiales y bronquiolares, hallazgos relacionados con asma, que está relacionado con el SCS la mayoría de las veces. El derrame pleural aparece en el 10\%-50\% de los pacientes, puede ser uni o bilateral y es causado por falla cardiaca izquierda que surge como resultado de pleuritis eosinofílica o cardiomiopatía ( - Fig. 5). ${ }^{6}$

\section{Granulomatosis con Poliangeitis (GP)}

La tríada clásica consiste en enfermedad pulmonar, sinusitis y glomerulonefritis, siendo los síntomas respiratorios altos (rinitis, sinusitis y otitis media) los que predominan. En los estadios iniciales de la enfermedad, en la radiografía de tórax se visualizan opacidades reticulares o nodulares bilaterales que predominan en las bases pulmonares. A medida que progresa la enfermedad, los nódulos aumentan en tamaño y número, pueden cavitarse y presentan predilección por los ápices pulmonares. Esas lesiones cavitadas presentan paredes gruesas y evolucionan a quistes de paredes finas e inclusive pueden desaparecer con el tratamiento. La TCMD pone de manifiesto nódulos pequeños y lesiones no visibles en la radiografía de tórax. Se ha descrito predominio de las lesiones a nivel subpleural. El signo del halo ha sido descripto en la GP, no es específico y corresponde a microinfartos del parénquima por el proceso angiocéntrico. El compromiso traqueobronquial queda demostrado por estenosis focal o difusa, masas de partes blandas intra o extraluminales y atelectasias segmentarias o lobares. Las anormalidades bronquiales son vistas en el $40 \%$ de los casos y, a diferencia de las lesiones del parénquima pulmonar, no se resuelven con el tratamiento ( - Figs. 6 y 7 ). ${ }^{14}$

\section{Granulomatosis sarcoidea necrosante}

Esa patología afecta exclusivamente al pulmón y representa una variante de la sarcoidosis. Predomina en el sexo femenino y se presenta en forma asintomática en el $15 \%-45 \%$ de los pacientes. Se caracteriza por presentar múltiples nódulos bilaterales con distribución subpleural y peribroncovascular que pueden cavitarse y realzan en forma heterogénea ante la administración de contraste. Los ganglios mediastinales pueden estar aumentados de tamaño y tener infiltración granulomatosa. Si existiese compromiso pleural se manifiesta con granulomas difusos y fibrosis organizada. Las características y la distribución de las lesiones tienen un gran parecido a la sarcoidosis. Sin embargo, la menor prevalencia de adenopatías hiliares y mediastinales y la propensión de las lesiones hacia la cavitación la distinguen de esa patología (-Fig. 8). ${ }^{14}$

\section{Síndrome de Sjögren}

El síndrome de Sjogren se caracteriza por infiltración linfocítica de las glándulas exócrinas lagrimales y salivales, lo que conduce a sequedad bucal y ocular. Puede ocurrir en forma aislada (síndrome de Sjögren primario), o como complicación de enfermedades autoinmunes (síndrome de Sjögren secundario). Las manifestaciones del compromiso pulmonar en el síndrome de Sjögren primario son: las anormalidades de la vía aérea y la neumonía intersticial. En TCMD de alta resolución, la inflamación crónica con infiltración linfoplasmocitaria y los cambios fibróticos de 


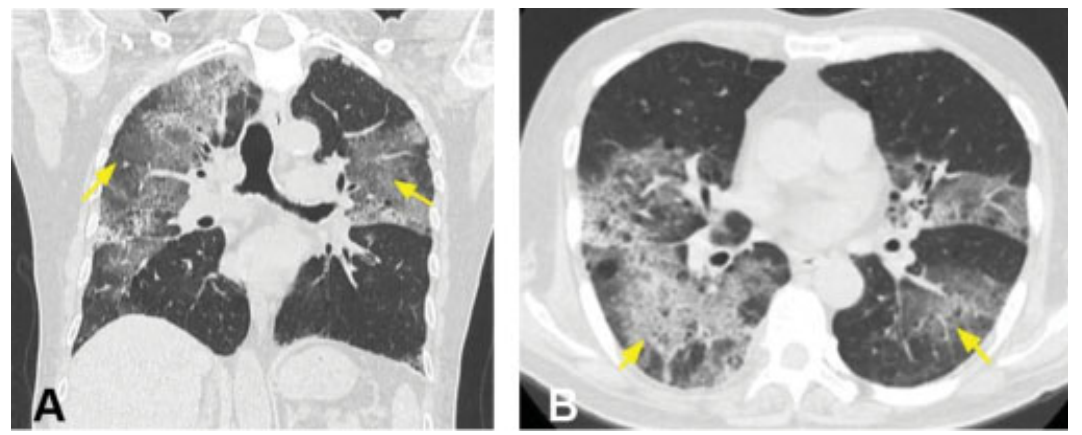

Fig. 6 Granulomatosis con poliangeitis (GP). TCMD de tórax. Plano coronal (A) y plano axial (B). Múltiples áreas parcheadas de aumento en la atenuación del parénquima en vidrio esmerilado, con compromiso difuso de ambos campos pulmonares (flechas), en paciente con hemoptisis y proteinuria. Los hallazgos del BAL son cambios inflamatorios con macrófagos con hemosiderina y eosinofilia moderada y el diagnóstico por biopsia renal es de granulomatosis con poliangeitis.

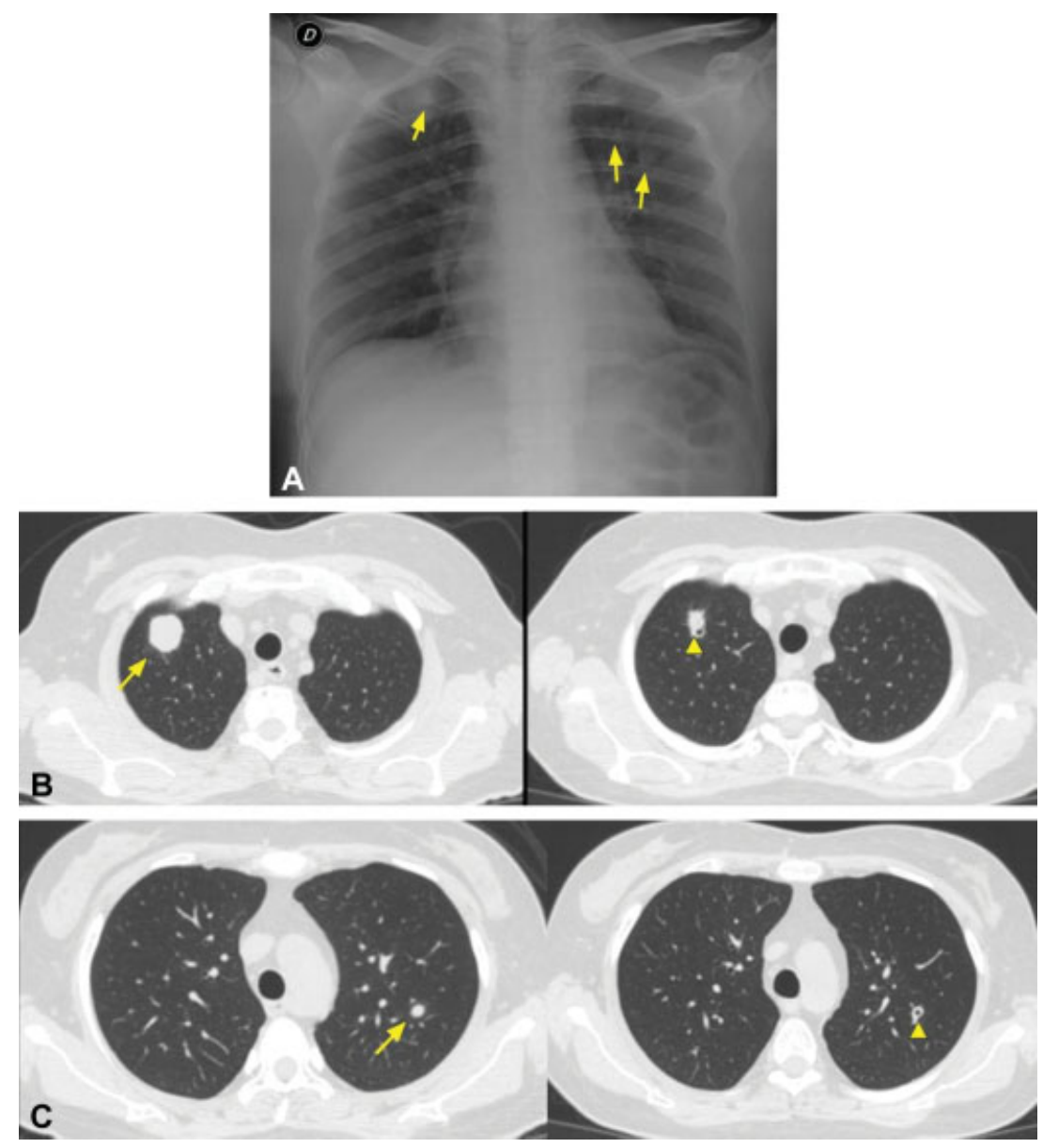

Fig. 7 Granulomatosis con poliangeitis. Rx de tórax, incidencia anteroposterior (A). Opacidad nodular proyectada en el tercio superior del campo pulmonar derecho y otras más pequeñas y menos definidas en el izquierdo (flecha). TCMD de tórax plano axial (B, C) que evidencia dos formaciones nodulares en ambos campos pulmonares, que en los controles posteriores evolucionan a la cavidad central (cabeza de flecha).

bronquios y bronquiolos terminales son vistos como bronquio o bronquioloectasias y engrosamientos de la pared bronquial. En ocasiones se observa aumento de la atenuación en mosaico, lo que indica bronquiolitis obstructiva, hallazgos que logran visualizarse mejor en una fase espiratoria. El patrón de neumonía intersticial más común es el de neumonía intersticial no específica, que se expresa como áreas de aumento de la atenuación en vidrio esmerilado y reticulares bilaterales, bronquiectasias por tracción, ambos de predominio basal y con distribución peribroncovascular. También pueden observarse múltiples quistes aéreos, que se observan como espacios aéreos redondos con paredes finas y tendencia a la distribución peribroncovascular. Las manifestaciones mediastínicas son la linfadenopatía, la 

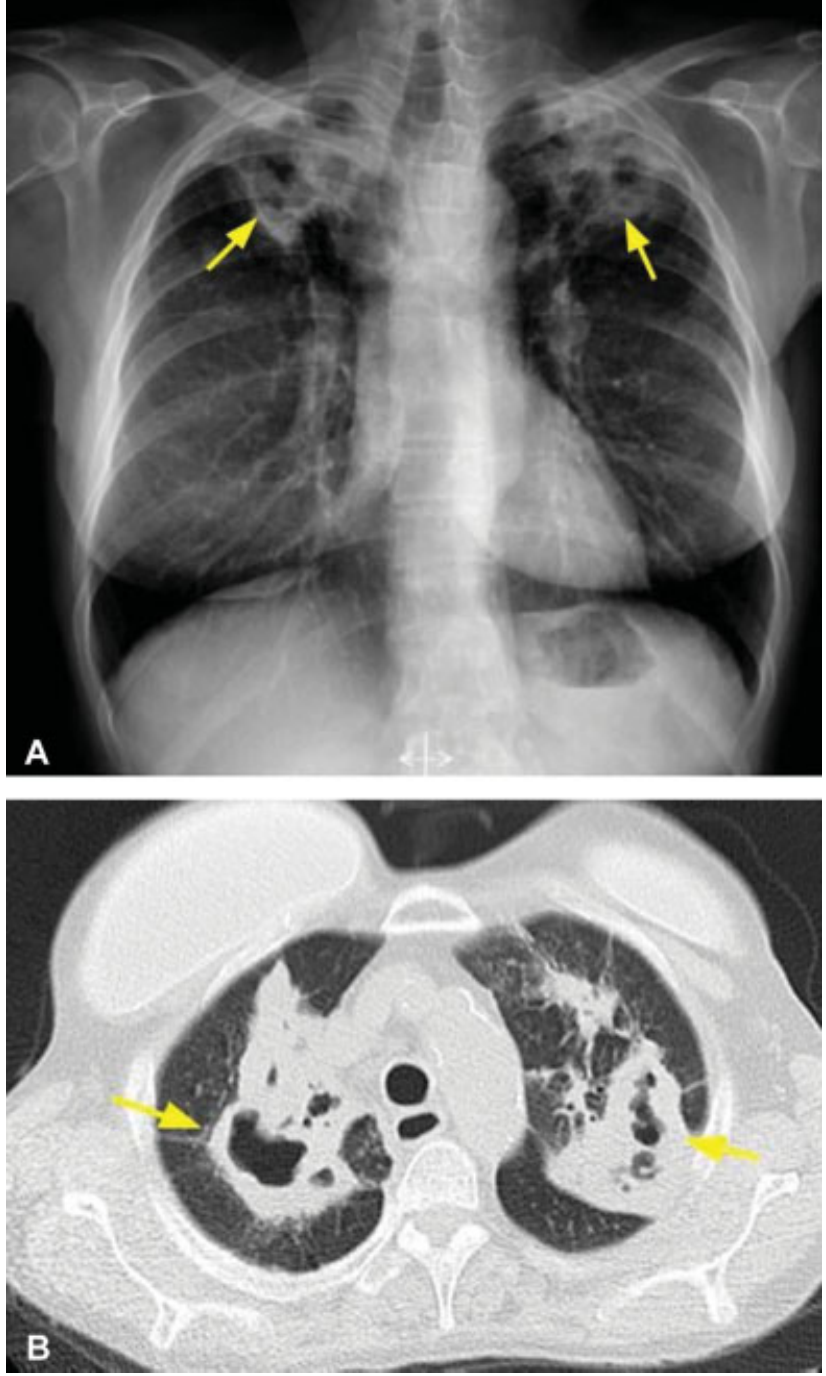

Fig. 8 Granulomatosis Sarcoidea Necrosante. Paciente femenina de 40 años, asintomática desde la perspectiva respiratoria que concurre a control anual. Rx de tórax de incidencia anteroposterior (A). Áreas con marcada disminución en la transparencia en ambos lóbulos superiores con sectores con cavitación central (flecha). TCMD de tórax (B).

Reducción en el volumen de ambos lóbulos superiores y compromiso de los segmentos apicales de ambos lóbulos inferiores. Descartadas todas las causas infecciosas, la biopsia pulmonar revela la presencia de inflamación granulomatosa con escasas áreas de necrosis.

hiperplasia linfoide del timo y los quistes tímicos multiloculares, visualizados en TCMD como múltiples nódulos y aumento de la atenuación del tejido anterior de la grasa mediastinal (- Fig. 9). ${ }^{15}$

\section{Conclusión}

Los síndromes eosinofílicos pulmonares representan un grupo heterogéneo de condiciones idiopáticas y secundarias que pueden afectar los espacios aéreos, la vasculatura o el intersticio. En la TCMD el reconocimiento del patrón, localización, distribución y severidad son valiosos para sugerir los diagnósticos diferenciales y guiar la terapéutica, en especial en estadios iníciales donde la radiología simple puede no evidenciar alteraciones. Creemos que es de suma

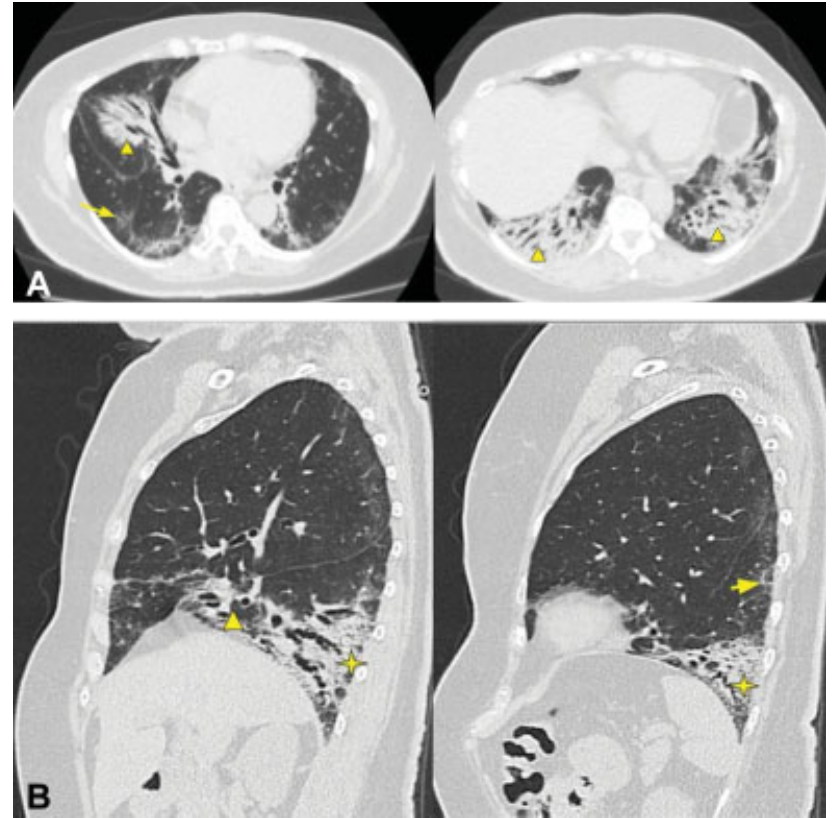

Fig. 9 Síndrome de Sjögren. TCMD plano axial y sagital (A, B). Paciente femenina de 64 años, que presenta en contexto de síndrome de Sjögren intersticiopatía con múltiples áreas de aumento en la atenuación en vidrio esmerilado" de distribución peribroncovascular y subpleural (flechas) que comprometen principalmente a ambos lóbulos inferiores, lóbulo medio y língula y, en menor medida, a los sectores más basales de ambos lóbulos superiores. En esas áreas se identifican algunas dilataciones bronquiales/ bronquiolares (cabeza de flecha). En los segmentos basales de ambos lóbulos inferiores, especialmente del derecho, se identifican algunas áreas con tendencia a la consolidación (estrella). Biopsia positiva para fibrosis e infiltrado linfocitario con eosinofilia.

utilidad correlacionar los hallazgos radiológicos con la epidemiología y la clínica del paciente para poder arribar a un diagnóstico final.

\section{Confidencialidad de los Datos}

Los autores declaran que han seguido los protocolos de su centro de trabajo sobre la publicación de datos de pacientes y que todos los pacientes incluidos en el estudio han recibido información suficiente y han dado su consentimiento informado por escrito.

\section{Conflicto de Intereses}

Los autores declaran no tener ningún conflicto de intereses.

\section{Bibliografía}

1 Egea N, Merlo A, Esponda L, Cazaux A, Cambursano VH, Cortés JR. [Lung eosinophilic syndrome: clinical presentation and cases report]. Rev Fac Cien Med Univ Nac Cordoba 2014;71(01):59-63

2 Bernheim A, McLoud T. A Review of Clinical and Imaging Findings in Eosinophilic Lung Diseases. AJR Am J Roentgenol 2017;208 (05):1002-1010

3 Cottin V. Eosinophilic Lung Diseases. Clin Chest Med 2016;37(03): 535-556

4 Price M, Gilman MD, Carter BW, Sabloff BS, Truong MT, Wu CC. Imaging of Eosinophilic Lung Diseases. Radiol Clin North Am 2016;54(06):1151-1164 
5 Jeong YJ, Kim KI, Seo IJ, et al. Eosinophilic lung diseases: a clinical, radiologic, and pathologic overview. Radiographics 2007;27(03): 617-637, discussion 637-639

6 Contrera M, Curbelo P, Meerovich E, Piñeyro L. Eosinofilias Pulmonares. Neumol Cir Torax 2006;65(S3):S47-S55

7 García-Peña P, Boixadera H, Barber I, Toran N, Lucaya J, Enríquez G. Thoracic findings of systemic diseases at high-resolution CT in children. Radiographics 2011;31(02):465-482

8 Akuthota P, Weller PF. Eosinophilic pneumonias. Clin Microbiol Rev 2012;25(04):649-660

9 Rose DM, Hrncir DE. Primary eosinophilic lung diseases. Allergy Asthma Proc 2013;34(01):19-25

10 Cheon JE, Lee KS, Jung GS, Chung MH, Cho YD. Acute eosinophilic pneumonia: radiographic and CT findings in six patients. AJR Am J Roentgenol 1996;167(05):1195-1199
11 Yoshida K, Shijubo N, Koba H, et al. Chronic eosinophilic pneumonia progressing to lung fibrosis. Eur Respir J 1994;7 (08):1541-1544

12 Kim Y, Lee KS, Choi DC, Primack SL, Im JG. The spectrum of eosinophilic lung disease: radiologic findings. J Comput Assist Tomogr 1997;21(06):920-930

13 Worthy SA, Müller NL, Hansell DM, Flower CDR. Churg-Strauss syndrome: the spectrum of pulmonary CT findings in 17 patients. AJR Am J Roentgenol 1998;170(02):297-300

14 Frazier AA, Rosado-de-Christenson ML, Galvin JR, Fleming MV. Pulmonary angiitis and granulomatosis: radiologic-pathologic correlation. Radiographics 1998;18(03):687-710, quiz 727

15 Egashira R, Kondo T, Hirai T, et al. CT findings of thoracic manifestations of primary Sjögren syndrome: radiologicpathologic correlation. Radiographics 2013;33(07):1933-1949 